\title{
Effect of a preoperative single-dose steroid on pulmonary function and postoperative symptoms after modified radical mastectomy: results of a randomized clinical trial
}

\author{
Jorge Jiménez-Tornero ${ }^{1}$, Ana Olivia Cortés-Flores ${ }^{1,2}$, Mariana Chávez-Tostado ${ }^{3}$, \\ Gilberto Morgan-Villela ${ }^{1}$, Carlos Zuloaga-Fernández del Valle ${ }^{1,2}$, \\ Raymundo Zuloaga-Fernández del Valle ${ }^{1,2}$, Luis Alberto García-González ${ }^{1}$, \\ Vanesa Sarahí Fernández-Avalos ${ }^{4}$, Roberto Carlos Miranda-Ackerman ${ }^{1}$, \\ Andrea Socorro Alvarez-Villaseñor ${ }^{5}$, Gabriela Ambriz-González ${ }^{6}$, Francisco José Barbosa-Camacho ${ }^{7}$, \\ Clotilde Fuentes-Orozco ${ }^{7}$, Vianca Seleste Contreras-Cordero ${ }^{7}$, Alejandro González-Ojeda ${ }^{7}$
}

${ }^{1}$ San Javier Hospital, Guadalajara, Jalisco, Mexico; ${ }^{2}$ ANKER Global Oncology, Guadalajara, Jalisco, Mexico; ${ }^{3}$ Department of Human Reproduction, Health Sciences University Center, Universidad de Guadalajara, Jalisco, México; ${ }^{4}$ Universitary Center of Tonala, University of Guadalajara, Guadalajara, Mexico; ${ }^{5}$ Medical Auxiliary Coordination of Health Research, Mexican Institute of Social Security, Baja California Sur, Mexico; ${ }^{6}$ Surgical Division, Pediatric Hospital, Western National Medical Center, Mexican Institute of Social Security, Guadalajara, Jalisco, Mexico; ${ }^{7}$ Biomedical Research Unit 02, Specialties Hospital of the Western National Medical Center, Mexican Institute of Social Security, Guadalajara, Jalisco, Mexico

Contributions: (I) Conception and design: All authors; (II) Administrative support: None; (III) Provision of study materials or patients: All authors; (IV) Collection and assembly of data: All authors; (V) Data analysis and interpretation: All authors; (VI) Manuscript writing: All authors; (VII) Final approval of manuscript: All authors.

Correspondence to: Alejandro González-Ojeda, MD, PhD, FACS. Biomedical Research Unit 02, Mexican Institute of Social Security, Avenida Belisario Domínguez \# 1000. Colonia Independencia, 44340, Guadalajara, Jalisco, Mexico. Email: avygail5@gmail.com.

Background: Evidence suggests that a preoperative single-dose steroid improves lung function and decreases the incidence of postoperative symptoms; however, this has not been sufficiently proved in modified radical mastectomy for cancer. This study aimed to evaluate the efficacy of preoperative single-dose steroid administration for postoperative lung function and postoperative symptoms in women undergoing modified radical mastectomy for breast cancer.

Methods: In this controlled clinical trial, conducted between June 2014 and October 2018, we examined 81 patients. Patients received a preoperative single dose of $8 \mathrm{mg}$ dexamethasone ( $=41$; treatment group) or placebo (sterile injectable water; $n=40$; control group). We obtained data on postoperative nausea and vomiting and pain intensity and performed spirometry $1 \mathrm{~h}$ before and $1,6,12$, and $24 \mathrm{~h}$ after surgery. The use of additional analgesic or antiemetic drugs was recorded. We followed up patients 30 days after discharge and recorded any surgical or medical complications.

Results: The age distribution and anthropometric variables of the two groups were similar. Almost $50 \%$ of the patients in each group also underwent breast reconstruction. In the treatment group, pain intensity was always lower, the incidence of postoperative nausea and vomiting was lower at 6,12 , and $24 \mathrm{~h}$, and additional analgesics or antiemetics were required less frequently $(\mathrm{P}<0.05$ for all). Both treatment and control groups demonstrated a restrictive ventilatory pattern immediately after surgery, which in the treatment group was reversed after $24 \mathrm{~h}$. However, the reconstructed patients had a more intense and prolonged restrictive pattern $(\mathrm{P}<0.05)$. Surgical morbidity included one seroma observed in the control group. No infections occurred at the surgical site or at any other level, and no patient developed any metabolic disorder. No mortality was observed in either group.

Conclusions: This study establishes that a single preoperative dose of dexamethasone markedly decreased the incidence of postoperative nausea and vomiting and pain, improved respiratory parameters, and decreased the need for additional postoperative analgesic or antiemetic drugs.

Clinical Trial Registration: ClinicalTrials.gov (ID NCT02305173). 
Keywords: Mastectomy; postoperative nausea and vomiting; postoperative pain; spirometry; steroids

Submitted Mar 17, 2020. Accepted for publication Aug 09, 2020.

doi: 10.21037 /gs-20-366

View this article at: http://dx.doi.org/10.21037/gs-20-366

\section{Introduction}

The Global Cancer Observatory (GLOBOCAN) predicted 18.1 million new cancer cases and 9.6 million cases of cancer-related death in 2018 (1). Among these, breast cancer was estimated to contribute 2.1 million new cases $(11.6 \%$ of total) and 627,000 cancer-related deaths (6.6\% of total) (1). In Mexico, as in many countries, the incidence of breast cancer has grown and it has become the most frequent malignant tumor in women, displacing carcinoma of the cervix, which occupied the first position for many years (2). Despite the implementation of screening programs, breast cancer is only detected early in $10 \%$ of patients (3). Therefore, locally advanced disease is still frequently diagnosed. In any case, limited or radical mastectomy is the cornerstone of breast cancer treatment for early or locally advanced disease (4).

Postoperative nausea and vomiting (PONV) and pain have been described as the "big little problem" (5-7). The risk of PONV is extremely high in women undergoing mastectomy and $60-80 \%$ of patients not receiving antiemetic medication develop it $(8,9)$. Emetic episodes can cause various complications, including gastric aspiration, wound dehiscence, psychological distress, and delayed recovery and discharge times (6). This justifies prophylactic administration of antiemetic medication (e.g., antihistamines, butyrophenones, and dopamine receptor antagonists) in women scheduled for breast cancer surgery. Antiemetic use is common in the multimodal management of PONV $(10,11)$. In addition, respiratory function is often compromised after major surgical procedures, especially thoracic and abdominal procedures performed under general anesthesia. Postoperative pain, surgical trauma to the thoracic wall, and a postoperative compressive chest dressing limit chest movement and lung expansion, occasionally causing hypoxemia (12).

Dexamethasone has been demonstrated to be an effective antiemetic agent in patients undergoing cancer chemotherapy (13). Although the antiemetic and analgesic effects of postoperative dexamethasone after various interventions have been reported (14), limited evidence exists for its beneficial effects on respiratory function in patients undergoing abdominal, thoracic, esophageal, or heart surgery. Although the efficacy of $4 \mathrm{mg}$ dexamethasone for preventing PONV after breast surgery was reported, its effect on postoperative pain was minimal (15). One study reported that administration of $8 \mathrm{mg}$ dexamethasone resulted in a marked reduction in PONV after breast cancer surgery (16). Another study analyzing the efficacy of $8 \mathrm{mg}$ betamethasone on the incidence of postoperative complications in 75 patients undergoing breast surgery with and without axillary lymph node dissection reported an $11 \%$ reduction in the cumulative incidence of $\mathrm{PONV}$ and a $40 \%$ reduction in postoperative pain compared with controls (17). However, these studies did not assess the respiratory effects of dexamethasone.

We recently reported the results of a randomized controlled trial of preoperative dexamethasone administration in patients undergoing breast-conserving mastectomy for early breast cancer (18). In that study, we observed a marked reduction in postoperative nausea and a swift reversal in postoperative restrictive pulmonary conditions.

Modified radical mastectomy (MRM) is an extensive surgical procedure involving a mandatory axillary lymph node dissection, which results in greater bleeding and prolonged operative time. This procedure is employed to treat locally advanced breast cancer. There is no evidence on the effect of administration of a single preoperative dose of steroids on respiratory function after this procedure.

Hence, this study aimed to evaluate the efficacy of preoperative single-dose steroid administration in decreasing pain and PONV, together with its effects on respiratory function in women undergoing MRM under general anesthesia with and without breast reconstruction. We present the following article in accordance with the CONSORT reporting checklist (available at http://dx. doi. org/10. 21037/gs-20-366). 


\section{Methods}

\section{Study design and study population}

This double-blind, randomized, placebo-controlled, parallel clinical trial, conducted between June 2014 and October 2018 , included 81 patients undergoing breast cancer surgery. All patients were scheduled to undergo unilateral MRM with axillary lymph node resection with or without immediate breast reconstruction with silicone implants. Full written informed consent was obtained from all patients before their inclusion in the study. Using sealed-envelope assignment, patients were randomly allocated to receive a single dose of $8 \mathrm{mg}$ intravenous (IV) dexamethasone or placebo (sterile injectable water) $1 \mathrm{~h}$ before the surgery. Allocation took place in a centralized center located outside the hospital whose personnel were blinded to the protocol and patients. The prepared syringes for dexamethasone and placebo were identical. They were handed over to the anesthesiologist together with the assignment key by operating room nurses, who were unaware of the study protocol. The patients, anesthesiologist, surgical team, floor nurses, and respiratory technicians were blinded to patient allocation.

\section{Eligibility criteria}

Inclusion criteria: Women between 25 and 70 years of age, with a confirmed diagnosis of breast cancer, stages IIA, IIB, and IIIA, American Society of Anesthesiologists (ASA) scores I and II, with or without a history of neoadjuvant chemotherapy, without any type of treatment, such as steroidal and nonsteroidal anti-inflammatory analgesics for four weeks before surgery, and scheduled for unilateral MRM. The women had to have normal kidney and liver function defined as a preoperative creatinine level of $<1.2 \mathrm{mg} / \mathrm{dL}$, total bilirubin $<1 \mathrm{mg} / \mathrm{dL}$, and no elevation of liver enzymes.

We excluded patients with ASA class III or IV physical status. Other exclusion criteria were: age >70 years; pregnancy; previous steroid therapy; uncontrolled diabetes mellitus (serum glycated hemoglobin level $>8 \%$ ); use of opioids, sedatives, or analgesics within 1 week before the surgery, any history of alcohol or drug abuse or previous chest radiotherapy. Furthermore, we excluded patients with a history of inner ear disease or uncontrollable severe PONV after any previous surgical procedure.

Patients were hospitalized on the day of surgery and were followed up for 30 days after discharge for medical or surgical complications. Surgical complications included surgical site infection, hemorrhage, hematoma, seroma, wound dehiscence, and flap necrosis. We inserted a closed drainage system in all patients, which was withdrawn when the output was $\leq 30 \mathrm{~mL}$ in $24 \mathrm{~h}$. Medical morbidity was classified as pulmonary, metabolic, or other complications, including atelectasis, pneumonia, pulmonary thromboembolism, hyperglycemia, deep or superficial thrombophlebitis, and urinary tract infection.

\section{Anesthesia and surgery}

The following standardized anesthetic protocol described previously by our group (18) was used in all patients. Local anesthesia or spinal block was not used in any case. Briefly, the protocol included the installation of a peripheral venous access under topical anesthesia. Patients received $\mathrm{IV}$ antibiotic prophylaxis with $1 \mathrm{~g}$ cephalothin $1 \mathrm{~h}$ before anesthesia. In the operating room, each patient underwent continuous noninvasive monitoring. According to their randomization, patients received a single-dose steroid or injectable water.

As premedication, IV midazolam $(0.1-0.2 \mathrm{mg} / \mathrm{kg}$ body weight) and fentanyl $(1 \mu \mathrm{g} / \mathrm{kg})$ were administered. Then, supplementary oxygen was administered using a face mask with $100 \%$ oxygen, and an attending anesthesiologist obtained basal hemodynamic values. Next, induction was performed using IV propofol (1-2 $\mathrm{mg} / \mathrm{kg}$ ) and completed with IV fentanyl $(3 \mu \mathrm{g} / \mathrm{kg})$ together with IV rocuronium $(0.6 \mathrm{mg} / \mathrm{kg})$. Assisted oxygenation continued at a rate of $5 \mathrm{~L} / \mathrm{min}$. Orotracheal intubation was performed in all patients. Tube diameter was selected according to each patient. Inspiratory oxygen was used during anesthesia and was maintained at $100 \%$ concentration. Intraoperatively, the medication was completed using IV omeprazole $(40 \mathrm{mg})$ and IV ondansetron $(4 \mathrm{mg})$. All patients were monitored using standard techniques for indirect assessment of blood pressure and heart rate, expired carbon dioxide content, and oxygen saturation of the blood. At the end of the mastectomy, the endotracheal tube was removed, and a compressing dressing was applied in each case to prevent complications such as bleeding and hematomas.

MRM includes the total resection of the mammary gland plus resection of axillary lymphatic nodes. Pectoral muscles were not removed. If it was advisable, immediate reconstruction was performed using a silicone implant placed behind the major pectoral muscle. The operative time was defined as the interval from the skin incision to 
skin closure. Endotracheal tube removal time was defined as the interval between intubation and endotracheal tube removal. Bleeding was defined as blood loss during the surgical procedure quantified by aspiration of blood and the weight of wet pads and sponges less the weight of dry ones. Patients were transferred to the recovery unit where they were monitored for approximately $60 \mathrm{~min}$ and were required to be fully awake before being moved to their rooms.

\section{Respiratory function}

All technical aspects of an adequate spirometry have been described previously by our group (18) in accordance with the recommendations published by Tan et al. (19). The patients of both study and control groups were provided with explanations regarding the spirometry using language they understood, and their cooperation was requested. The first function test was conducted at rest in a quiet and calm environment with no audiovisual disturbances and before being transferred to the operating room. A qualified evaluator explained and demonstrated the forced expiratory maneuver to ensure that patients understood the maneuver and to avoid measurement bias. Overall, three satisfactory maneuvers were required from a maximum of eight attempts for each measurement, which were performed at intervals of $>30 \mathrm{~s}$ and recorded using a Sibelmed ${ }^{\circledR}$ Datospir 110/120 spirometer with a Fleisch pneumotachograph (SIBELGroup, Barcelona, Spain). We recorded the highest value of the three successful maneuvers as the definitive result. Measurements included the forced expiratory volume in $1 \mathrm{~s}\left(\mathrm{FEV}_{1}\right)$, forced vital capacity (FVC), peak expiratory flow (PEF), and the ratio of $\mathrm{FEV}_{1}$ to $\mathrm{FVC}\left(\mathrm{FEV}_{1} / \mathrm{FVC}\right)$ before surgery and at $1,6,12$, and $24 \mathrm{~h}$ after the surgical procedure.

\section{Analgesic and antiemetic therapy}

Nonsteroidal anti-inflammatory drugs were used as analgesics after surgery with IV sodium ketorolac $(30 \mathrm{mg}$ every $6 \mathrm{~h}$ ). A numeric pain rating scale (NPRS) was used to record pain intensity, in which 0 reflects no pain and 10 reflects the most severe and intolerable pain (20). Pain intensity was recorded when patients awoke in the recovery room and at 6,12 , and $24 \mathrm{~h}$ after the surgery. If the rating for pain at rest was $>6$, a $2.5-\mathrm{mg}$ infusion of morphine in $100 \mathrm{~mL}$ of $0.9 \%$ saline solution was administered. During the time intervals, we performed respiratory function tests and evaluated the analgesic or antiemetic drugs used within those periods.

PONV was recorded in the recovery room and at 6 , 12 , and $24 \mathrm{~h}$ after surgery using a 3 -point ordinal scale (0: asymptomatic; 1: a feeling of nausea or retching without oral expulsion of gastric contents; 2: vomiting). We defined nausea as an unpleasant sensation related to the awareness of an urge to vomit. Retching was defined as labored, spasmodic, and rhythmic contraction of respiratory muscles without gastric content expulsion. Vomiting was defined as the forceful expulsion of gastric contents from the mouth. We used IV ondansetron $(4 \mathrm{mg})$ to treat all these symptoms. Patient monitoring was performed directly by the surgeons involved in the surgical procedure. Patients visited them at least twice after surgery. The first visit was for removal of stitches or drainage tube and a second visit 30 days after surgery as end of follow-up. In addition, each patient reported any symptoms directly to surgeons by phone during the 30-day monitoring period.

We registered all postoperative respiratory or surgical complications during hospitalization and 30 days after discharge. The collected data included age, body mass index (BMI), smoking history, associated allergies, chronic diseases, neoadjuvant chemotherapy, operative and endotracheal tube removal times, amount of bleeding, and the frequency of use of analgesic or antiemetic agents.

\section{Statistical analysis}

In this study, the sample size was predetermined with an anticipated $35 \%$ difference in the occurrence of nausea and vomiting between groups; the anticipated $\alpha$ error was 0.05 and $\beta$ error 0.20 , and the power calculation suggested that 35 patients in each group would be sufficient. All data are presented as crude numbers, percentages, and mean \pm standard deviation. We tested every quantitative variable for the equality of variance using Levene's test to confirm the normal distribution of continuous variables. Analysis was performed using Student's $t$-test, and the $\chi^{2}$ test or Fisher's exact test was used for qualitative data. The $95 \%$ confidence intervals of the differences were also calculated. We considered $\mathrm{P}<0.05$ significant. We conducted statistical analyses using Excel 2007 (Microsoft, Redmond, WA, USA) and IBM SPSS Statistics (version 20 for Windows; IBM SPSS, Armonk, NY, USA). 


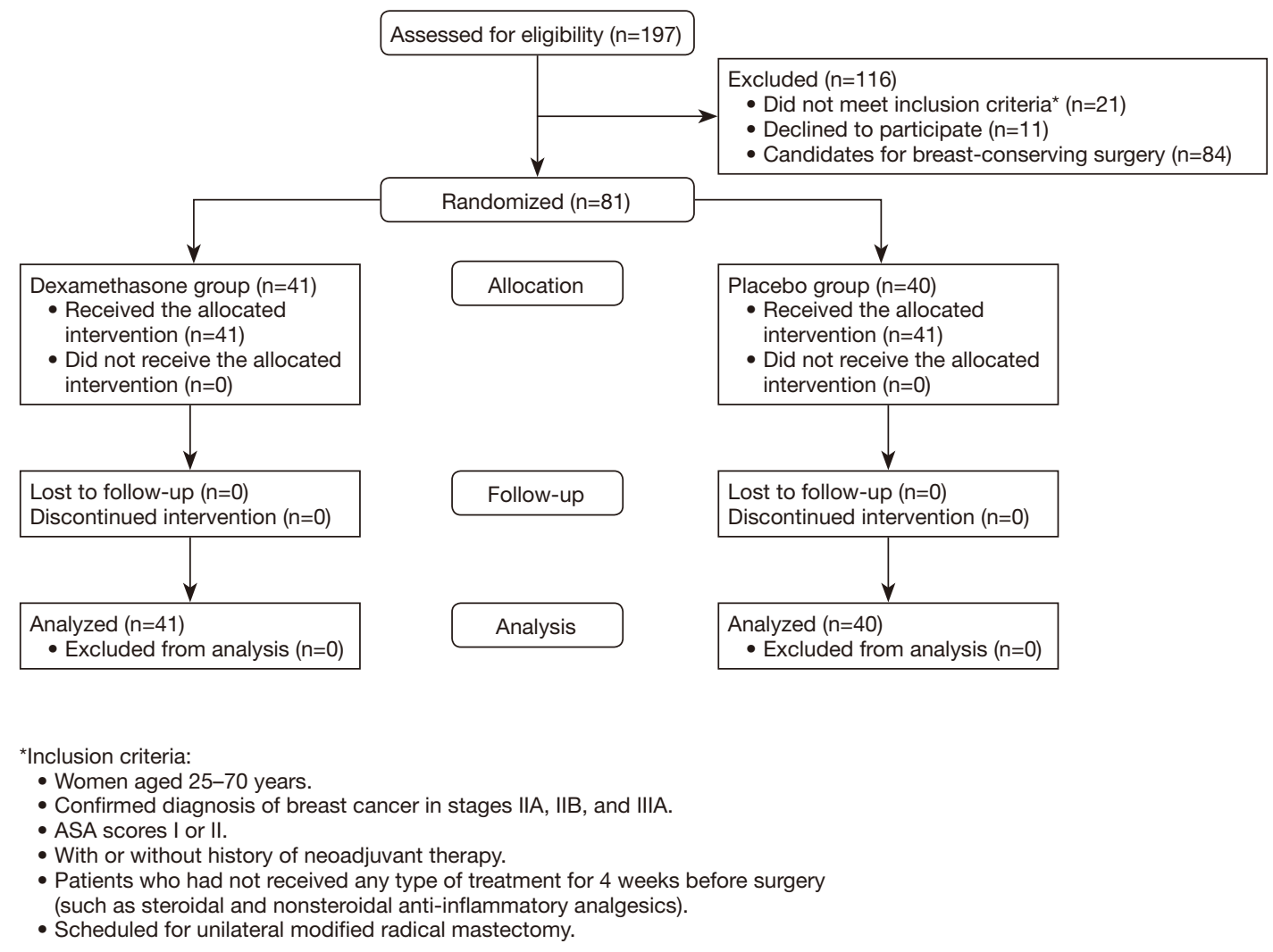

Figure 1 Patient enrollment flowchart.

\section{Ethics}

The clinical trial was conducted according to the principles of the Declaration of Helsinki (as revised in 2013) and Mexican Health Guidelines. The study was approved by the Ethics Committee of the Specialties Hospital of the Western National Medical Center (ID 2011-1301-74) and registered at the ClinicalTrials.gov database (ID NCT02305173). Full written informed consent was obtained from all patients before their inclusion in the study.

\section{Results}

Figure 1 presents the selection process of patients. All included patients completed the follow-up. Age and anthropometric measures (BMI) did not differ between the groups $(\mathrm{P}=0.13$ and $\mathrm{P}=0.73)$. The most frequent comorbid condition observed in both groups was type 2 diabetes mellitus $(\mathrm{P}=0.67)$. Tobacco was used by $9.7 \%$ and $15 \%$ patients in the study and control groups, respectively $(\mathrm{P}=0.47)$. Five patients in each group required neoadjuvant therapy $(\mathrm{P}=0.87)$ with four cycles of doxorubicin and cyclophosphamide (every 3 weeks) and four cycles of docetaxel (every 21 days). The surgical procedure was carried out 1 month after the end of the last chemotherapy cycle. As shown in Table 1, all patients underwent MRM, but 20 patients in each group also underwent immediate breast reconstruction in the same surgical procedure $(\mathrm{P}=0.91)$. Operative time $(\mathrm{P}=0.16)$, transoperative bleeding $(\mathrm{P}=0.64)$, and time to removal of endotracheal tube $(\mathrm{P}=0.40)$ did not differ between groups. The closed drainage system was removed around 7 days after surgery $(\mathrm{P}=0.48)$.

The analysis of postoperative symptoms (Table 2) revealed that the treatment group had markedly less pain, and that nausea and vomiting were less frequent at 6 and $12 \mathrm{~h}$. The morphine requirement was higher at 6 and $12 \mathrm{~h}$ in the control group than in the treatment group $(\mathrm{P}=0.04$ and $\mathrm{P}=0.02$, respectively). Antiemetic medication use was higher in the control group than in the treatment group at the same time points $(\mathrm{P}=0.03$ and $\mathrm{P}=0.03$, respectively).

Spirometry results are presented in Table 3. Respiratory parameters decreased to approximately $25 \%$ of the basal values in both groups at $1 \mathrm{~h}$ after surgery. In the treatment 
Table 1 General characteristics of patients undergoing modified radical mastectomy (MRM) for cancer

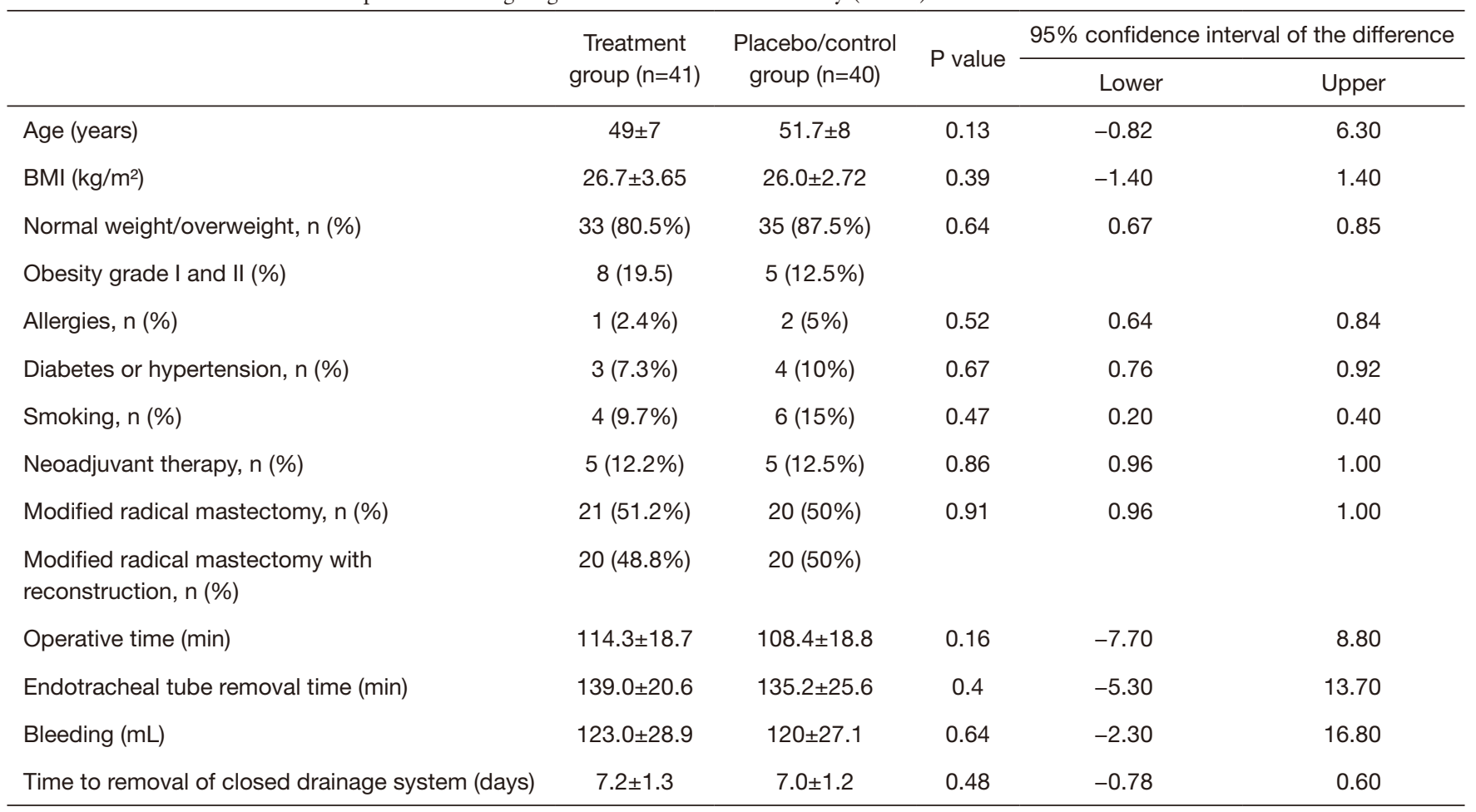

Values are expressed as means \pm standard deviation. BMI, body mass index.

group, we observed a substantial recovery in $\mathrm{FEV}_{1}$ during the postoperative period. The values at $24 \mathrm{~h}$ were nearly equal to the baseline values. Moreover, $\mathrm{FEV}_{1}, \mathrm{FVC}$, and $\mathrm{PEF}$ values were higher in the treatment group than in the control group $(\mathrm{P}<0.01)$. We observed marked differences in the $\mathrm{FEV}_{1} / \mathrm{FVC}$ ratio at 1 and $6 \mathrm{~h}$ after surgery $(\mathrm{P}=0.001$ and $\mathrm{P}=0.01$, respectively) and the oximetry percentages between the groups at $12 \mathrm{~h}(\mathrm{P}=0.03)$, although we did not observe an oxygen level $<90 \%$ in any patient at any point.

Almost $50 \%$ of the patients underwent immediate breast reconstruction. The general characteristics of these patients are described in Table 4. They were younger and had a lower BMI than those women who underwent MRM alone $(\mathrm{P}=0.002$ and $\mathrm{P}=0.01$ respectively), but there were no differences in their allergies, medical history, smoking habits, and previous neoadjuvant chemotherapy $(\mathrm{P}=0.60$, $\mathrm{P}=0.85, \mathrm{P}=0.51, \mathrm{P}=0.5)$. Because the combined procedure was longer than MRM alone, the operative time, duration of orotracheal intubation, transoperative bleeding, and time to removal of drains were greater than for the MRM only group $(\mathrm{P}=0.001, \mathrm{P}=0.001, \mathrm{P}=0.001, \mathrm{P}=0.009)$.

Table 5 shows the intensity of the pain and PONV. Patients who underwent immediate reconstruction had more intense pain at all postoperative points $(\mathrm{P}<0.05)$. The incidence of PONV was higher, but the difference was not significant $(\mathrm{P}>0.1)$, although these patients had a greater need for narcotics and antiemetics at $6 \mathrm{~h}$ and $12 \mathrm{~h}$ postoperatively $(\mathrm{P}<0.05)$. The respiratory function tests described in Table 6 indicated significant differences in $\mathrm{FEV}_{1}, \mathrm{FVC}$, and PEF up to $12 \mathrm{~h}$ after surgery $(\mathrm{P}<0.05)$. At $24 \mathrm{~h}$, there was partial recovery of the restrictive pattern, but in patients undergoing immediate reconstruction, these values did not reach the baseline values.

Surgical morbidity included one seroma observed in the control group, which was drained by puncture without complications. No infections occurred at the surgical site or at any other level, and no patient developed any metabolic disorder. No mortality was observed in either group during the study.

\section{Discussion}

Our results showed that the preoperative administration of dexamethasone $(8 \mathrm{mg})$ markedly decreased pain, PONV, and the need for analgesics and antiemetics after MRM for cancer under total IV anesthesia. Both groups showed 
Table 2 Postoperative pain, nausea, vomiting, and additional analgesic and antiemetic doses

\begin{tabular}{|c|c|c|c|c|c|}
\hline & $\begin{array}{l}\text { Treatment group } \\
\qquad(\mathrm{n}=41)\end{array}$ & $\begin{array}{l}\text { Placebo/control } \\
\text { group }(n=40)\end{array}$ & $P$ value & \multicolumn{2}{|c|}{$95 \%$ confidence interval of the difference } \\
\hline \multicolumn{6}{|c|}{ Pain (NPRS scale 0-10) } \\
\hline $1 \mathrm{~h}$ & $4.7 \pm 1.7$ & $5.8 \pm 2.8$ & 0.011 & 0.31 & 1.8 \\
\hline $6 \mathrm{~h}$ & $2.7 \pm 0.9$ & $3.7 \pm 1.8$ & 0.002 & 0.66 & 1.7 \\
\hline $24 \mathrm{~h}$ & $0.8 \pm 0.7$ & $1.5 \pm 1.3$ & 0.001 & 0.21 & 0.98 \\
\hline \multicolumn{6}{|c|}{ Nausea (\%) } \\
\hline $1 \mathrm{~h}$ & $9.7 \%$ & $25 \%$ & 0.08 & 0.05 & 0.19 \\
\hline $6 \mathrm{~h}$ & $17.1 \%$ & $37.5 \%$ & 0.03 & 0.002 & 0.097 \\
\hline \multicolumn{6}{|c|}{ Vomiting (\%) } \\
\hline $1 \mathrm{~h}$ & $2.4 \%$ & $12.5 \%$ & 0.10 & 0.11 & 0.28 \\
\hline $6 \mathrm{~h}$ & $4.9 \%$ & $20 \%$ & 0.04 & 0.00 & 0.08 \\
\hline $12 \mathrm{~h}$ & $2.4 \%$ & $17.5 \%$ & 0.03 & 0.00 & 0.06 \\
\hline $24 \mathrm{~h}$ & 0 & $7.5 \%$ & 0.11 & 0.05 & 0.20 \\
\hline \multicolumn{6}{|c|}{ Additional morphine doses (\%) } \\
\hline $1 \mathrm{~h}$ & $17.1 \%$ & $27.5 \%$ & 0.25 & 0.26 & 0.47 \\
\hline $6 \mathrm{~h}$ & $4.9 \%$ & $20 \%$ & 0.04 & 0.002 & 0.09 \\
\hline $12 \mathrm{~h}$ & $12.2 \%$ & $32.5 \%$ & 0.03 & 0.00 & 0.08 \\
\hline $24 \mathrm{~h}$ & $4.9 \%$ & $12.5 \%$ & 0.26 & 0.17 & 0.37 \\
\hline
\end{tabular}

Pain was recorded using a numeric pain rating scale (NPRS) from 0 to 10 based on patients' perceived symptoms at the times of measurements. Values are expressed as means \pm standard deviation. Nausea, vomiting, and additional drug doses are expressed as the percentages of patients who presented with these symptoms or required the drugs within the indicated time periods.

marked suppression of respiratory function, but this condition was almost reversed after $24 \mathrm{~h}$ in the treatment group. No pulmonary complications were observed in either group. Those patients who underwent reconstruction after the MRM reported more pain and required more analgesics and antiemetics. Although the severity of PONV did not differ significantly between these patients and those who did not undergo reconstruction, the incidence was higher. This lack of significance was most likely because $50 \%$ of the subgroup of reconstructed patients received dexamethasone. Respiratory function in these patients revealed a deeper restrictive pattern that, unlike that in the unreconstructed group, failed to reach baseline values by $24 \mathrm{~h}$ after the intervention.

Logistic regression models have identified several risk factors for PONV, enabling adequate prophylaxis in selected 
Table 3 Comparison of spirometry results between the study and control groups

\begin{tabular}{|c|c|c|c|c|c|}
\hline & $\begin{array}{c}\text { Treatment } \\
\text { group }(n=41)\end{array}$ & $\begin{array}{l}\text { Placebo/control } \\
\text { group }(n=40)\end{array}$ & $P$ value & \multicolumn{2}{|c|}{$95 \%$ confidence interval of the difference } \\
\hline \multicolumn{6}{|c|}{ Forced expiratory volume in $1 \mathrm{~s}\left(\mathrm{FEV}_{1}\right)$ in liters } \\
\hline Basal & $2.2 \pm 0.30$ & $2.1 \pm 0.36$ & 0.15 & -0.25 & 0.04 \\
\hline $1 \mathrm{~h}$ & $1.6 \pm 0.43$ & $1.3 \pm 0.40$ & 0.003 & -0.46 & -0.09 \\
\hline $12 \mathrm{~h}$ & $1.8 \pm 0.38$ & $1.4 \pm 0.52$ & 0.001 & -0.58 & -0.17 \\
\hline $24 \mathrm{~h}$ & $2.1 \pm 0.60$ & $1.7 \pm 0.49$ & 0.001 & -0.60 & -0.12 \\
\hline \multicolumn{6}{|c|}{ Forced vital capacity (FVC) in liters } \\
\hline Basal & $2.3 \pm 0.32$ & $2.2 \pm 0.52$ & 0.25 & -0.30 & 0.80 \\
\hline $12 \mathrm{~h}$ & $2.0 \pm 0.35$ & $1.7 \pm 0.45$ & 0.001 & -0.57 & -0.21 \\
\hline $24 \mathrm{~h}$ & $2.2 \pm 0.58$ & $1.8 \pm 0.60$ & 0.004 & -0.66 & -0.13 \\
\hline \multicolumn{6}{|c|}{ Peak expiratory flow (PEF) in liters } \\
\hline Basal & $4.0 \pm 1.7$ & $3.8 \pm 1.3$ & 0.64 & -0.81 & 0.50 \\
\hline $1 \mathrm{~h}$ & $3.0 \pm 1.3$ & $2.1 \pm 0.72$ & 0.001 & -1.04 & 0.43 \\
\hline $6 \mathrm{~h}$ & $3.4 \pm 1.5$ & $2.1 \pm 1.3$ & 0.001 & -1.8 & -0.53 \\
\hline $12 \mathrm{~h}$ & $3.6 \pm 1.1$ & $2.7 \pm 1.24$ & 0.03 & -1.1 & -0.06 \\
\hline $24 \mathrm{~h}$ & $4.1 \pm 1.5$ & $3.0 \pm 1.4$ & 0.001 & -1.8 & -0.54 \\
\hline $24 \mathrm{~h}$ & $89.0 \pm 4.1$ & $90.0 \pm 6.8$ & 0.20 & -0.83 & 4.13 \\
\hline \multicolumn{6}{|c|}{ Oxygen saturation in percentage $\left(\mathrm{O}_{2}\right)$} \\
\hline Basal & $97.4 \pm 2.0$ & $97.3 \pm 1.8$ & 0.96 & -0.88 & 0.84 \\
\hline $1 \mathrm{~h}$ & $96.0 \pm 2.4$ & $96.0 \pm 1.6$ & 0.52 & -0.61 & 1.20 \\
\hline $6 \mathrm{~h}$ & $96.0 \pm 2.0$ & $94.8 \pm 2.2$ & 0.09 & -2.23 & 0.12 \\
\hline $12 \mathrm{~h}$ & $96.4 \pm 1.9$ & $95.2 \pm 2.8$ & 0.03 & -2.14 & -0.90 \\
\hline $24 \mathrm{~h}$ & $97.0 \pm 2.0$ & $96.1 \pm 2.5$ & 0.18 & -1.69 & 0.33 \\
\hline
\end{tabular}

Values are expressed as means \pm standard deviation. 
Table 4 General characteristics of patients undergoing modified radical mastectomy (MRM) with and without immediate reconstruction for breast cancer

\begin{tabular}{|c|c|c|c|c|c|}
\hline & $\begin{array}{l}\text { MRM and immediate breast } \\
\text { reconstruction }(n=40)\end{array}$ & $\begin{array}{l}\text { MRM alone } \\
\quad(n=41)\end{array}$ & $P$ value & \multicolumn{2}{|c|}{$95 \%$ confidence interval of the difference } \\
\hline Age (years) & $47.6 \pm 7.2$ & $53.2 \pm 8.2$ & 0.002 & 2.13 & 9.0 \\
\hline BMI $\left(\mathrm{kg} / \mathrm{m}^{2}\right)$ & $25.4 \pm 2.8$ & $27.1 \pm 3$ & 0.01 & -1.92 & 2.55 \\
\hline Normal weight \& overweight & 35 & 33 & 0.39 & 0.14 & 0.32 \\
\hline Allergies (n) & $1(2.5 \%)$ & $2(4.9 \%)$ & 0.60 & 0.41 & 0.62 \\
\hline Diabetes or hypertension (n) & $3(7.5 \%)$ & $4(9,7 \%)$ & 0.85 & 0.46 & 0.67 \\
\hline Smoking (n) & $6(15 \%)$ & $4(9.7 \%)$ & 0.51 & 0.35 & 0.2 \\
\hline Neoadjuvant therapy (n) & $6(15 \%)$ & $4(9.7 \%)$ & 0.5 & 0.46 & 0.67 \\
\hline Bleeding (mL) & $124.6 \pm 19.5$ & $102.7 \pm 18.4$ & 0.001 & -30.2 & -13.4 \\
\hline $\begin{array}{l}\text { Time to removal of closed drainage } \\
\text { system (days) }\end{array}$ & $7.6 \pm 1.3$ & $6.6 \pm 1.2$ & 0.009 & -1.55 & -0.23 \\
\hline
\end{tabular}

Values are expressed as means \pm standard deviation. BMI, body mass index.

patients (21-23). At least four critical risk factors have been identified, including female gender, a history of vestibular diseases and/or previous PONV after surgery, the absence of a smoking history, and opioid use. The incidence rates of PONV were reported to be $10 \%, 23 \%, 39 \%, 61 \%$, and $79 \%$ in patients with none, one, two, three, or four of these factors, respectively $(24,25)$.

In addition to these previously described risk factors, the duration of the surgical procedure influences the incidence and intensity of postoperative symptoms; with every additional $30 \mathrm{~min}$ of operating time, the presence of pain and nausea increases significantly by up to $60 \%$ (23). Although smoking can have a deleterious effect on respiratory function, it appears to offer protection against nausea and vomiting (12). Less than $10 \%$ of our patients smoked and the distribution was comparable in both groups. All patients received opioids during anesthesia, a widely recognized factor in promoting the development of PONV, and those in the control group received more narcotics for pain management.

Since dexamethasone was introduced as an effective antiemetic drug (13), research has established its efficacy in preventing nausea and vomiting after different surgical procedures. The biological actions of glucocorticoids start within 1-2 $\mathrm{h}$ of administration; however, the mechanism underlying the antiemetic effect of dexamethasone remains unclear. Reportedly, one possible mechanism could be the central inhibition of prostaglandin synthesis, which hinders the release of endogenous opioids and alters the permeability of the blood-brain barrier to serum proteins (26,27). Glucocorticoids exert analgesic effects primarily through the peripheral inhibition of phospholipase, which decreases the production of metabolites of the cyclooxygenase pathway and the activity of lipoxygenase during the inflammatory response. In addition, the immune response of patients receiving dexamethasone shifts in an anti-inflammatory direction demonstrated by a shift toward suppressed interleukin (IL)-6 and increased IL-10 levels. Patients experiencing less pain suffer fewer postoperative complications $(14,15,28)$.

Several factors, including general anesthesia, can affect pulmonary function via different effects on the respiratory system, e.g., by altering the control of breathing, respiratory muscle activity, residual functional capacity, and distribution of alveolar ventilation/perfusion, or by causing atelectasis. Furthermore, anesthetic agents can affect different areas of the central nervous system that control breathing patterns and respiratory muscle activities $(29,30)$. 
Table 5 Postoperative pain, nausea, vomiting, and additional analgesic and antiemetic doses in patients undergoing MRM with and without immediate reconstruction

\begin{tabular}{|c|c|c|c|c|c|}
\hline & \multirow{2}{*}{$\begin{array}{l}\text { MRM and immediate breast } \\
\text { reconstruction }(n=40)\end{array}$} & \multirow{2}{*}{$\begin{array}{l}\text { MRM alone } \\
\quad(n=41)\end{array}$} & \multirow{2}{*}{$P$ value } & \multicolumn{2}{|c|}{$95 \%$ confidence interval of the difference } \\
\hline & & & & Lower & Upper \\
\hline \multicolumn{6}{|c|}{ Pain (NPRS scale 0-10) } \\
\hline $1 \mathrm{~h}$ & $7.0 \pm 1.2$ & $4.8 \pm 2.2$ & 0.001 & -2.2 & -0.98 \\
\hline $6 \mathrm{~h}$ & $4.4 \pm 1.1$ & $3.1 \pm 1.7$ & 0.001 & -1.40 & -0.29 \\
\hline $12 \mathrm{~h}$ & $2.7 \pm 0.9$ & $1.8 \pm 1.2$ & 0.001 & -1.15 & -0.28 \\
\hline $24 \mathrm{~h}$ & $1.5 \pm 0.9$ & $1 \pm 0.9$ & 0.04 & -0.78 & -0.11 \\
\hline \multicolumn{6}{|c|}{ Nausea (\%) } \\
\hline $1 \mathrm{~h}$ & $20 \%$ & $14.6 \%$ & 0.52 & 0.96 & 1.0 \\
\hline $6 \mathrm{~h}$ & $30 \%$ & $24.4 \%$ & 0.57 & 0.56 & 0.76 \\
\hline $12 \mathrm{~h}$ & $30 \%$ & $17.1 \%$ & 0.17 & 0.05 & 0.19 \\
\hline $24 \mathrm{~h}$ & $12.5 \%$ & $7.3 \%$ & 0.48 & 0.30 & 0.51 \\
\hline \multicolumn{6}{|c|}{ Vomiting (\%) } \\
\hline $1 \mathrm{~h}$ & $12.5 \%$ & $2.4 \%$ & 0.10 & 0.02 & 0.15 \\
\hline $6 \mathrm{~h}$ & $17.5 \%$ & $7.3 \%$ & 0.19 & 0.10 & 0.27 \\
\hline $12 \mathrm{~h}$ & $15 \%$ & $4.9 \%$ & 0.15 & 0.10 & 0.27 \\
\hline $24 \mathrm{~h}$ & $5 \%$ & $4.9 \%$ & 0.61 & 0.96 & 1.0 \\
\hline \multicolumn{6}{|c|}{ Additional morphine doses (\%) } \\
\hline $1 \mathrm{~h}$ & $30 \%$ & $14.6 \%$ & 0.25 & 0.07 & 0.23 \\
\hline $6 \mathrm{~h}$ & $20 \%$ & $4.9 \%$ & 0.04 & 0.02 & 0.13 \\
\hline $12 \mathrm{~h}$ & $17.5 \%$ & $2.4 \%$ & 0.03 & 0.00 & 0.08 \\
\hline $24 \mathrm{~h}$ & $5 \%$ & $4.9 \%$ & 0.98 & 0.96 & 1.0 \\
\hline \multicolumn{6}{|c|}{ Additional ondansetron doses (\%) } \\
\hline $1 \mathrm{~h}$ & $27.5 \%$ & $14.6 \%$ & 0.15 & 0.71 & 0.23 \\
\hline $6 \mathrm{~h}$ & $37.5 \%$ & $17.1 \%$ & 0.04 & 0.00 & 0.08 \\
\hline $12 \mathrm{~h}$ & $30 \%$ & $14.6 \%$ & 0.09 & 0.02 & 0.15 \\
\hline $24 \mathrm{~h}$ & $12.5 \%$ & $4.9 \%$ & 0.26 & 0.09 & 0.25 \\
\hline
\end{tabular}

Pain was recorded using a numeric pain rating scale (NPRS) from 0 to 10 based on patients' perceived symptoms at the times of measurements. Values are expressed as means \pm standard deviation. Nausea, vomiting, and additional drug doses are expressed as the percentages of patients who presented with these symptoms or required the drugs within the indicated time periods.

An intraoperative reduction in the functional residual capacity of the lungs in the absence of pulmonary comorbidities has been reported; such deterioration occurs at the induction of anesthesia and remains stable intraoperatively (12). Different mechanisms can exacerbate this during anesthesia and after surgery, such as the decreased diameter of the chest wall, changes in the diaphragmatic shape and position, and redistribution of the thoracic blood volume. A reduction in the thoracic diameter is related to a reduction in the inspiratory muscular tone, which could cause alterations in chest wall recoil properties.

Furthermore, compressive dressings used at the end of breast surgery contribute to decreasing the chest wall movement by decreasing the internal diameter of the rib 
Table 6 Comparison of spirometry results between patients submitted to MRM with or without immediate reconstruction

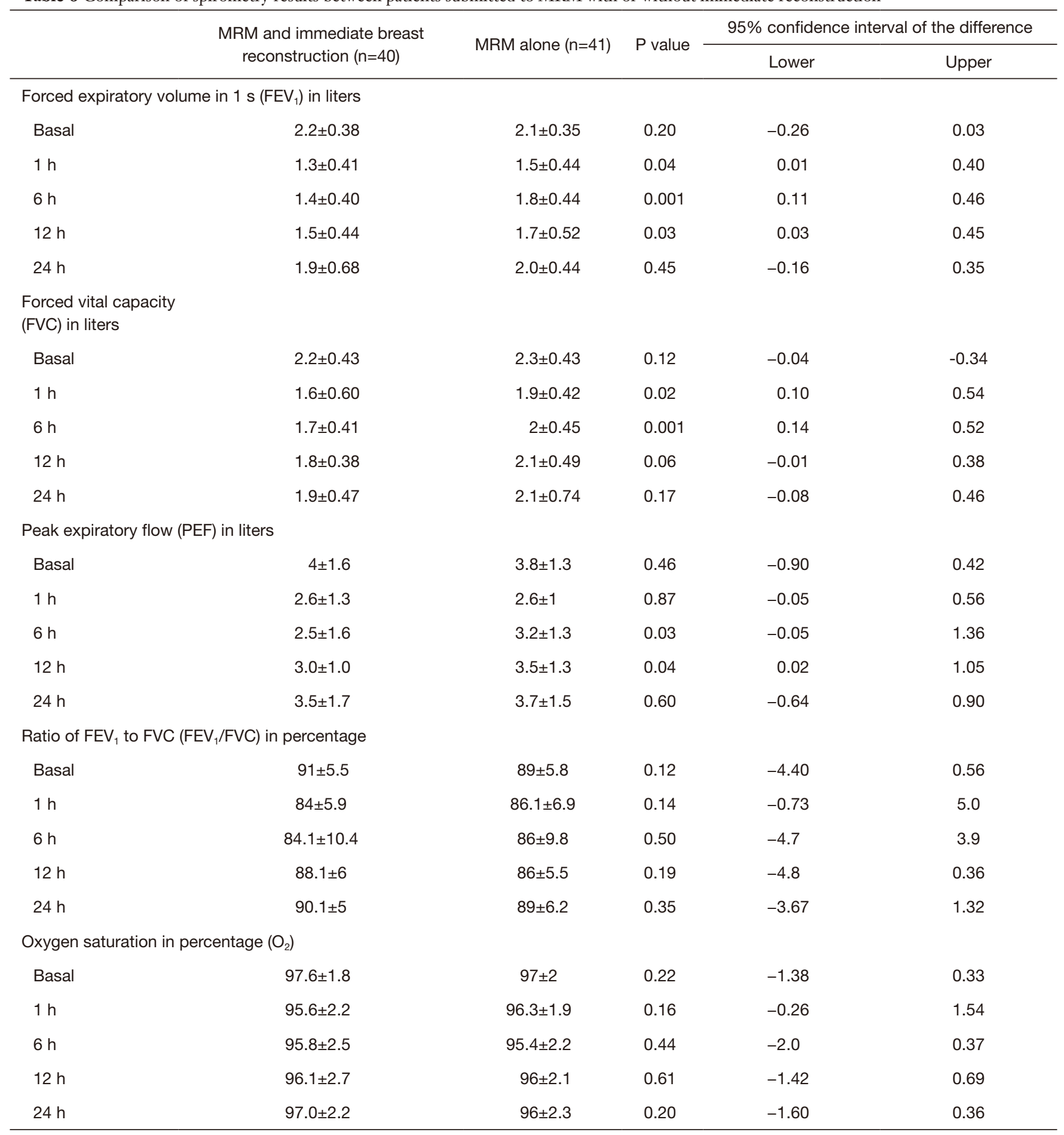

Values are expressed as means \pm standard deviation. 
cage, which decreases the lung volume. Reportedly, the loss of muscle tone and an increase in the intraabdominal pressure could favor a cephalic shift of the diaphragm, contributing to a further reduction in the functional residual capacity $(31,32)$. Atelectasis occurs in almost all patients following general anesthesia, predominantly in the dependent lung zones; mechanisms that could account for its occurrence include small-airway collapse, lung compression, lung surfactant deficiency, and redistribution of alveolar gas. Small-airway collapse is attributed to the reduction in the closing capacity (12). A supine position during surgery promotes atelectasis because of the presence of a gradient in the transpulmonary pressure associated with the increase in the intraabdominal pressure.

Changes in transpulmonary and intraabdominal pressures could result in lung compression and collapse (33). Although the impairment of lung surfactant production remains debatable, the use of volatile anesthetics and high inspiratory oxygen pressure could alter the permeability of the alveolar barrier and inactivate the surfactant. The redistribution of intra-alveolar gases in the presence of a high inspiratory oxygen concentration and an increase in the ventilation-perfusion ratio correlate with absorption atelectasis, which is more severe when accompanied by small-airway collapse $(32,33)$. All these etiological mechanisms of postoperative respiratory dysfunction could have contributed to or caused changes in spirometry values in our patients. These changes reflected a restrictive ventilatory pattern, including a decrease in $\mathrm{FVC}$ of $\geq 25 \%$, reduction in $\mathrm{FEV}_{1}$ with a nearly normal $\mathrm{FEV}_{1} / \mathrm{FVC}$ ratio, and reduction in PEF, which reflects a reduction in the chest wall distensibility and decreased expiratory effort (33).

Opioid-induced respiratory depression after surgery is a well-established risk factor, which can be manifest as oversedation, respiratory arrest, and the need for resuscitation. In a review of 357 patients with respiratory depression, 92 cases involved opioids, $53 \%$ of which involved opioid use, mainly morphine, for pain control; almost all cases involved multiple modalities of administration and continuous infusion, and $88 \%$ of cases occurred within $24 \mathrm{~h}$ of the surgical procedure (34). Other risk factors involved in respiratory depression include the use of CNS depressant drugs such as sedatives (barbiturates and antihistamines) and tricyclic antidepressants. However, in the present study, we observed no respiratory depression, possibly because we used opioids only as rescue medication for moderate-to-severe pain and in low dosages with a slow infusion under strict monitoring.
The scientific evidence highlights the prophylactic effect of steroids on pain intensity, the incidence of PONV, and reversal of a restrictive pattern of respiratory function (35). Furthermore, it has been shown that the administration of $8 \mathrm{mg}$ of dexamethasone in the perioperative period can increase the efficacy and duration of a single-shot multilevel paravertebral block in breast cancer surgery and reduce the intensity of postoperative pain, morphine consumption, and PONV incidence (36). The optimum therapeutic effect of dexamethasone appears to be achieved with a single dose of precisely $8 \mathrm{mg}$ intravenously. A higher dose such as 24 $\mathrm{mg}$ does not make a difference in pain intensity and PONV incidence after mastectomy; indeed, Steinthorsdottir et al. demonstrated that it increased the incidence of seromas after mastectomy (37).

Our study has some limitations. First, we adhered to a strict anesthesia protocol that is probably unlike the protocols used in the few controlled clinical trials available on this topic (15-18). For example, all patients had a physical status of ASA class I or II and were aged $<70$ years. We also used opioids, which are recognized to induce PONV, for anesthesia induction and postoperative pain control. However, the protocol for anesthesia induction and postoperative pain control was the same for patients receiving dexamethasone and the placebo. Second, all patients had reduced respiratory parameters in the immediate postoperative period, which recovered to baseline values by $24 \mathrm{~h}$ in patients who received dexamethasone. However, our observations were limited to the first $24 \mathrm{~h}$ after surgery. Nevertheless, there were no major postoperative morbidities in either group. Third, almost half (40/81) of the patients in our cohort underwent immediate breast reconstruction with silicone prostheses. Autologous reconstruction procedures, such as pedicled transverse rectus abdominis musculocutaneous flaps, were not considered in our study. Hence, our results cannot be extrapolated to patients undergoing such reconstruction procedures because these procedures involve both the chest and abdomen. A controlled trial in this patient population is required to determine the usefulness of preoperative steroids and their effects on PONV, pain, and respiratory function.

In conclusion, based on our study results and despite its limitations, we propose that preoperative single-dose steroid administration is effective in decreasing PONV incidence and pain intensity and causes a rapid reversal of the restrictive respiratory condition in patients undergoing MRM with or without breast reconstruction. 


\section{Acknowledgments}

We thank the participants of the study for their collaboration. We are especially grateful for the contribution of Dr. Domingo Lizardi-Garcia, a specialist in pneumology and lung physiology, for his contribution in conducting the initial spirometry studies. Sadly, Dr. Lizardi-Garcia passed away in 2016. We also thank the professional editing service Online English (https://www.oleng.com.au) for reviewing the manuscript for language, structure, and expression of ideas suitable for publication in the biomedical literature.

Funding: A grant from the Health Research Fund of the Mexican Institute of Social Security partially supported the study (FIS/IMSS/PROTMD11/995).

\section{Footnote}

Reporting Checklist: The authors have completed the CONSORT reporting checklist. Available at http://dx. doi. org/10. 21037/gs-20-366

Data Sharing Statement: Available at http://dx.doi. org/10.21037/gs-20-366

Peer Review File: Available at http://dx. doi. org/10.21037/ gs-20-366

Conflicts of Interest: All authors have completed the ICMJE uniform disclosure form (available at http://dx.doi. org/10.21037/gs-20-366). The authors have no conflicts of interest to declare.

Ethical Statement: The authors are accountable for all aspects of the work in ensuring that questions related to the accuracy or integrity of any part of the work are appropriately investigated and resolved. The protocol was approved by the Research Ethics Committee of the Specialties Hospital of the Western National Medical Center (ID 2011-1301-74) and was registered with the ClinicalTrials.gov database (ID NCT02305173). The authors assert that all procedures contributing to this work comply with the ethical standards of the relevant national and institutional committees on human experimentation and with the Helsinki Declaration of 1975 , as revised in Fortaleza, Brazil, in 2013 and the Mexican Health Guidelines. We obtained full written informed consent from all patients included in the study.
Open Access Statement: This is an Open Access article distributed in accordance with the Creative Commons Attribution-NonCommercial-NoDerivs 4.0 International License (CC BY-NC-ND 4.0), which permits the noncommercial replication and distribution of the article with the strict proviso that no changes or edits are made and the original work is properly cited (including links to both the formal publication through the relevant DOI and the license). See: https://creativecommons.org/licenses/by-nc-nd/4.0/.

\section{References}

1. Bray F, Ferlay J, Soerjomataram I, et al. Global cancer statistics 2018: GLOBOCAN estimates of incidence and mortality worldwide for 36 cancers in 185 countries. CA Cancer J Clin 2018;68:394-424.

2. Gómez Dantés O, Sesma S, Becerril VM, et al. [The health system of Mexico]. Salud Publica Mex 2011;53:s220-32.

3. Rodríguez-Cuevas S, Guisa-Hohenstein F, LabastidaAlmendaro S. First breast cancer mammography screening program in Mexico: Initial results 2005-2006. Breast J 2009;15:623-31.

4. Arce-Salinas C, Lara-Medina FU, Alvarado-Miranda A, et al. Evaluation of breast cancer treatment at a tertiary-level institution with Popular Health Insurance in Mexico. Rev Invest Clin 2012;64:9-16.

5. Kovac AL. Prevention and treatment of postoperative nausea and vomiting. Drugs 2000;59:213-43.

6. Watcha MF, White PF. Postoperative nausea and vomiting: Its etiology, treatment, and prevention. Anesthesiology 1992;77:162-84.

7. Fisher DM. The "big little problem" of postoperative nausea and vomiting: Do we know the answer yet? Anesthesiology 1997;87:1271-3.

8. Hammas B, Thörn SE, Wattwil M. Superior prolonged antiemetic prophylaxis with a four-drug multimodal regimen-comparison with propofol or placebo. Acta Anaesthesiol Scand 2002;46:232-7.

9. Oddby-Muhrbeck E, Jakobsson J, Andersson L, et al. Postoperative nausea and vomiting. A comparison between intravenous and inhalation anaesthesia in breast surgery. Acta Anaesthesiol Scand 1994;38:52-6.

10. Sadhasivam S, Saxena A, Kathirvel S, et al. The safety and efficacy of prophylactic ondansetron in patients undergoing modified radical mastectomy. Anesth Analg 1999;89:1340-5.

11. Chatterjee S, Rudra A, Sengupta S. Current concepts in the management of postoperative nausea and vomiting. 
Anesthesiol Res Pract 2011;2011:748031.

12. Tusman G, Böhm SH, Warner DO, et al. Atelectasis and perioperative pulmonary complications in high-risk patients. Curr Opin Anaesthesiol 2012;25:1-10.

13. Aapro MS, Alberts DS. Dexamethasone as an antiemetic in patients treated with cisplatin. $\mathrm{N}$ Engl J Med 1981;305:520.

14. Holte K, Kehlet H. Perioperative single-dose glucocorticoid administration: Pathophysiologic effects and clinical implications. J Am Coll Surg 2002;195:694-712.

15. Wattwil M, Thörn SE, Lövqvist $\AA$, et al. Dexamethasone is as effective as ondansetron for the prevention of postoperative nausea and vomiting following breast surgery. Acta Anaesthesiol Scand 2003;47:823-7.

16. Gómez-Hernández J, Orozco-Alatorre AL, DomínguezContreras $M$, et al. Preoperative dexamethasone reduces postoperative pain, nausea and vomiting following mastectomy for breast cancer. BMC Cancer 2010;10:692.

17. Olanders KJ, Lundgren GAE, Johansson AMG. Betamethasone in prevention of postoperative nausea and vomiting following breast surgery. J Clin Anesth 2014;26:461-5.

18. Cortés-Flores AO, Jiménez-Tornero J, Morgan-Villela $\mathrm{G}$, et al. Effects of preoperative dexamethasone on postoperative pain, nausea, vomiting and respiratory function in women undergoing conservative breast surgery for cancer: Results of a controlled clinical trial. Eur J Cancer Care (Engl) 2018;27. doi: 10.1111/ecc.12686.

19. Tan WC, Bourbeau J, O'Donnell D, et al. Quality assurance of spirometry in a population-based study predictors of good outcome in spirometry testing. COPD 2014;11:143-51.

20. Ferreira-Valente MA, Pais-Ribeiro JL, Jensen MP. Validity of four pain intensity rating scales. Pain 2011;152:2399-404.

21. Apfel CC, Greim CA, Haubitz I, et al. A risk score to predict the probability of postoperative vomiting in adults. Acta Anaesthesiol Scand 1998;42:495-501.

22. Koivuranta M, Läärä E, Snåre L, et al. A survey of postoperative nausea and vomiting. Anaesthesia 1997;52:443-9.

23. Sinclair DR, Chung F, Mezei G. Can postoperative nausea and vomiting be predicted? Anesthesiology 1999;91:109-18.
24. Apfel CC, Läärä E, Koivuranta $M$, et al. A simplified risk score for predicting postoperative nausea and vomiting: Conclusions from cross-validations between two centers. Anesthesiology 1999;91:693-700.

25. Smessaert A, Schehr CA, Artusio JF. Nausea and vomiting in the immediate postanesthetic period. J Am Med Assoc 1959;170:2072-6.

26. Jenkins LC, Lahay D. Central mechanisms of vomiting related to catecholamine response: Anaesthetic implication. Can Anaesth Soc J 1971;18:434-41.

27. Livrea P, Trojano M, Simone IL, et al. Acute changes in blood-CSF barrier permselectivity to serum proteins after intrathecal methotrexate and CNS irradiation. J Neurol 1985;231:336-9.

28. van den Heuvel SAS, van der Wal SEI, Bronkhorst EM, et al. Acute cytokine response during breast cancer surgery: Potential role of dexamethasone and lidocaine and relationship with postoperative pain and complicationsanalysis of three pooled pilot randomized controlled trials. J Pain Res 2020;13:1243-54.

29. Vargas M, Brunetti I, Pelosi P. Protective mechanical ventilation during general anaesthesia. Trends Anaesth Crit Care 2013;3:77-81.

30. Garcia AJ 3rd, Zanella S, Koch H, et al. Chapter 3networks within networks: The neuronal control of breathing. Prog Brain Res 2011;188:31-50.

31. Milic-Emili J, Torchio R, D’Angelo E. Closing volume: A reappraisal (1967-2007). Eur J Appl Physiol 2007;99:567-83.

32. Pelosi P, Negrini D. Extracellular matrix and mechanical ventilation in healthy lungs: Back to baro/volotrauma? Curr Opin Crit Care 2008;14:16-21.

33. Stanojevic S, Wade A, Stocks J, et al. Reference ranges for spirometry across all ages: A new approach. Am J Respir Crit Care Med 2008;177:253-60.

34. Lee LA, Caplan RA, Stephens LS, et al. Postoperative opioid-induced respiratory depression: A closed claims analysis. Anesthesiology 2015;122:659-65.

35. Jacobs A, Lemoine A, Joshi GP, et al; PROSPECT Working Group collaborators. PROSPECT guideline for oncological breast surgery: A systematic review and procedure-specific postoperative pain management recommendations. Anaesthesia 2020;75:664-73.

36. Bakeer AH, Abdallah NM, Kamel MA, et al. The impact of intravenous dexamethasone on the efficacy and duration 
of analgesia of paravertebral block in breast cancer surgery: A randomized controlled trial. J Pain Res 2018;12:61-7.

37. Steinthorsdottir KJ, Awada HN, Abildstrøm H, et al.

Cite this article as: Jiménez-Tornero J, Cortés-Flores AO, ChávezTostado M, Morgan-Villela G, Zuloaga-Fernández del Valle C, Zuloaga-Fernández del Valle R, García-González LA, FernándezAvalos VS, Miranda-Ackerman RC, Alvarez-Villaseñor AS, Ambriz-González G, Barbosa-Camacho FJ, Fuentes-Orozco C, Contreras-Cordero VS, González-Ojeda A. Effect of a preoperative single-dose steroid on pulmonary function and postoperative symptoms after modified radical mastectomy: results of a randomized clinical trial. Gland Surg 2020;9(5):13131327. doi: $10.21037 /$ gs-20-366
Dexamethasone dose and early postoperative recovery after mastectomy: A double-blind, randomized trial. Anesthesiology 2020;132:678-91. 